\title{
The Utility of Procalcitonin as a Biomarker to Limit the Duration of Antibiotic Therapy in Adult Sepsis Patients
}

\author{
Ronald S. Chamberlain ${ }^{1,2,3^{*}}$, Brian J. Shayota ${ }^{1,3}$, Carl Nyberg1,3, Prasanna Sridharan ${ }^{1}$ \\ ${ }^{1}$ Department of Surgery, Saint Barnabas Medical Center, Livingston, USA \\ ${ }^{2}$ Department of Surgery, New Jersey Medical School, Rutgers University, Newark, USA \\ ${ }^{3}$ Saint George's University School of Medicine, Grenada, West Indies \\ Email: *rchamberlain@barnabashealth.org
}

Received 23 May 2014; revised 22 June 2014; accepted 19 July 2014

Copyright (C) 2014 by authors and Scientific Research Publishing Inc.

This work is licensed under the Creative Commons Attribution International License (CC BY).

http://creativecommons.org/licenses/by/4.0/

c) (i) Open Access

\section{Abstract}

Introduction: With rising global antibiotic resistance, stewardship programs aimed at controlling multi-drug resistant (MDR) pathogens have begun to gain acceptance. These programs stress appropriate antibiotic selection, dosage and duration. A growing literature suggests serum procalcitonin (PCT) levels may be useful in guiding antibiotic duration and de-escalation. This report sought to evaluate the evidence-based data available from prospective randomized controlled trials (RCT) on the role of PCT in guiding reductions in antibiotic duration in adult sepsis patients. Methods: A comprehensive search of all published prospective RCT(s) on the use of PCT as a tool for guiding antibiotic therapy in adult sepsis patients was conducted using PubMed, Medline Plus and Google Scholar (2007-2013). Keywords searched included, "procalcitonin”, “sepsis-therapy”, "sepsis biomarker", “antibiotic duration", "drug de-escalation”, and "antimicrobial stewardship". Results: Four RCT(s) involving 826 adult sepsis patients have evaluated the role of serum PCT levels to guide criteria for cessation of antibiotic therapy based either on specific PCT levels or PCT kinetics. Bouadma et al. $(\mathrm{N}=621)$ stopped antibiotics when the PCT concentration was $<80 \%$ of the peak PCT value, or the absolute PCT concentration was $<0.5 \mu \mathrm{g} / \mathrm{L}$. The PCT arm showed a 2.7-day reduction in antibiotics. Schroeder et al. $(\mathrm{N}=27)$ discontinued antibiotics if clinical signs of infection improved and the PCT value decreased to $<1 \mathrm{ng} / \mathrm{mL}$ or to $<35 \%$ of the initial value within three days. The PCT arm had a 1.7-day reduction in antibiotics. Hochreiter et al. $(\mathrm{N}=110)$ ceased antibiotics when the PCT decreased to $<1 \mathrm{ng} / \mathrm{mL}$, or to $25 \%-35 \%$ of the initial value over three days if the value was $>1 \mathrm{ng} / \mathrm{mL}$. The PCT arm showed a 2-day reduction in antibiotics. Finally, Nobre et al. $(\mathrm{N}=68)$ stopped antibiotics when PCT levels decreased by $90 \%$ or more from the initial value, but not prior to Day 3 (if baseline PCT measured <1 $\mu \mathrm{g} / \mathrm{L}$ ) or Day 5 (if baseline PCT measured $\geq 1 \mu \mathrm{g} / \mathrm{L}$ ). The PCT arm showed a 4-day reduction in antibiotics. Overall, reduction of

\footnotetext{
"Corresponding author.
} 
PCT levels to $10 \%-35 \%$ of the initial concentration, to $<80 \%$ of the peak PCT value, or to an absolute PCT value of $<1 \mu \mathrm{g} / \mathrm{L}$ warranted antibiotic discontinuation 1.7 to 4 days earlier. No study reported a significant difference in mortality between the PCT arm and the control arm $(p<0.05)$. Conclusions: PCT-guided early cessation of antibiotic therapy in adult sepsis patients is associated with a significant decrease in antibiotic days, with no effect on overall mortality. Measurement of serum PCT levels may have a role in antimicrobial stewardship programs aimed at limiting antibiotic therapy duration, decreasing the selective pressure on drug-resistant bacterial strains and reducing hospital costs.

\section{Keywords}

Procalcitonin, Sepsis Therapy, Sepsis Biomarker, Antibiotic Duration, Antibiotic De-Escalation, Antimicrobial Stewardship

\section{Introduction}

Sepsis, a medical condition characterized by systemic inflammation in the presence of an infectious process (Table 1), has burdened inpatient facilities for decades with mortality rates ranging from 27\% to 54\% [1] [2]. Sepsis represents a serious public health threat to inpatient safety on a global scale. Recent Healthcare Cost and Utilization Project (HCUP) statistics have shown that septicemia, the sixth most frequent primary inpatient diagnosis in 2009, and hospital stays for septicemia overall increased by 153\% between 1993 and 2009 [3] [4]. Hospital stays for sepsis incurred a healthcare cost of \$15.4 billion in 2009, with an average annual cost growth of $11.9 \%$ per year between 1997 and 2008 [4] [5]. The increases in sepsis-related hospitalization, associated with rising costs of therapy make it incumbent upon medical professionals to develop new cost-reduction strategies while simultaneously achieving optimal clinical outcomes.

In the modern antibiotic era, treatment protocols for sepsis necessitate the rapid institution of broad-spectrum antibiotics, often empirically, as delayed antimicrobial therapy is associated with both increased morbidity and mortality [1] [6]-[10]. Harbarth et al. [6] reported that patients treated with inappropriate initial antibiotic therapy had a 39\% 28-day mortality, while those who received appropriate treatment had a $24 \%$ mortality rate, demonstrating that inappropriate therapy was independently associated with increased mortality (OR $=1.8$; $95 \%$ CI, 1.2 - 2.6). Kumar et al. [8] described a strong association between delayed administration of antibiotics and in-hospital mortality in septic patients with hypotension (OR = 1.119 per hour of delay; 95\% CI, 1.103 - 1.136),

Table 1. The American college of chest physicians and the society of critical care medicine criteria for diagnosis of sepsis [47].

\begin{tabular}{|c|c|}
\hline Parameter & Value \\
\hline Body temperature & $\begin{array}{l}\text { - }<36^{\circ} \mathrm{C}\left(97^{\circ} \mathrm{F}\right) \text {; or } \\
\text { - }>38^{\circ} \mathrm{C}\left(100^{\circ} \mathrm{F}\right)\end{array}$ \\
\hline Heart rate & - $>90$ beats per minute \\
\hline Respiratory rate & $\begin{array}{l}\text { - }>20 \text { breaths per minute; or } \\
\text { - Blood gas } \mathrm{PaCO}_{2}<32 \mathrm{~mm} \mathrm{Hg}(4.3 \mathrm{kPa})\end{array}$ \\
\hline WBC count & $\begin{array}{l}\text { - } \quad<4000 \text { cells } / \mathrm{mm}^{3}\left(4 \times 10^{9} \text { cells/L); or }\right. \\
\text { - }>12,000 \text { cells } / \mathrm{mm}^{3}\left(12 \times 10^{9} \text { cells/L); or }\right. \\
\text { - }>10 \% \text { band forms (immature WBCs) }\end{array}$ \\
\hline Infection & $\begin{array}{l}\text { - Clinically suspected; or } \\
\text { - Proven (by stain, culture, PCR) }\end{array}$ \\
\hline
\end{tabular}

Abbreviations: $\mathrm{PaCO}_{2}=$ Partial pressure of arterial carbon dioxide, $\mathrm{WBC}=$ white blood cell, $\mathrm{PCR}=$ polymerase chain reaction . 
noting proper administration within the first hour of hypotension was associated with $79.9 \%$ survival with a decrease of $7.6 \%$ per hour of delayed administration. However, while the recommendation for early antibiotics is supported by evidence-based data, the choice of which antimicrobial regimen to use as well as the duration is largely subjective, varying from practitioner to practitioner [11]. Thursky et al. [12] reported that controlling antimicrobial decision-making in the ICU using a computerized system (thereby defeating arbitrary drug regimen/duration choice) led to decreased use of carbapenems ( $\mathrm{OR}=0.61 ; 95 \% \mathrm{CI}, 0.39-0.97$ ), third-generation cephalosporins (OR = 0.58; 95\% CI, 0.42 - 0.79) and vancomycin (OR = 0.67; 95\% CI, $0.45-1.00)$, a 10.5\% reduction in total antibiotic use, fewer microbial susceptibility mismatches (OR $=0.63 ; 95 \% \mathrm{CI}, 0.39$ - 0.98) and an increased frequency of de-escalation to narrow spectrum antibiotics. Arbitrary use of antibiotics has led to well-documented overuse, with anywhere from $22 \%$ to $65 \%$ of all hospital antibiotics being deemed inappropriate [13] [14]. Moreover, the lack of standardized therapy, paired with the indiscriminate use of antibiotics and a lack of significant oversight has resulted in serious implications on the cost of medical care [15]-[25]. More importantly, this trend has contributed to the global emergence of multi-drug resistant (MDR) bacterial strains [11] [12]. Finland et al. [26] documented the development of antibiotic resistance over the course of forty years (1935-1975), citing resistance in strains of streptococcus sp., staphylococcus sp. and other virulent organisms. Since then, several additional experts have reported a link between antibiotic use and the development of resistance, highlighting the importance of reducing the use of unnecessary antibiotics [27] [28].

More recently, the implementation of antimicrobial stewardship programs (ASPs) has garnered a great deal of interest in an effort to limit antibiotic use globally. The primary focus of ASPs are to assure appropriate antibiotic selection, dosage and duration [29], with the goals of minimizing selective pressure on bacterial strains and maximizing "clinical impact and longevity" of antibiotics [30]. ASPs, which stress appropriate custom-tailored therapeutic regimens on a per-patient basis [31], also aim to reduce healthcare expenditures [11] and adverse effects caused by prolonged antibiotic exposure [11] [32] [33]. The foundational precepts of ASPs were described as early as the 1990s, with a 1996 study by Goldmann et al. outlining a number of strategic goals aimed at optimizing antibiotics use [34]. Since then, studies by Apisarnthanarak et al. [35], Tseng et al. [36], Allerberger et al. [37] [38] and several others have described the successful international implementation of ASPs in Thailand, Taiwan and the European Union, with a recent report by George et al. [39] suggesting the institution of ASPs in ICU settings universally. It is anticipated that ASPs may ultimately become a cornerstone of efforts towards forestalling the growth of MDR pathogens [40].

Within ASPs themselves, there exist a number of potential strategic measures that may be utilized to reduce the incidence of MDR pathogens, including but not limited to antibiotic cycling (routine changes in antibiotic type at regular time intervals) [41]-[43], antibiotic mixing (random changes in antibiotic type on a continuous basis) [44] [45] and antibiotic de-escalation [30], though the effectiveness of each of these strategies is controversial [41]-[45]. A comprehensive literature review of antibiotic cycling by Kollef et al. [44] cited 7 reports defending its use, along with 2 studies presenting disputing data. The authors noted that current studies lack standardized prescribing practices, susceptibilities and outcome measures and are fraught with limitations and confounders, leading them to conclude that cycling is usually of limited use as a standalone strategy [44]. In contrast, a nine-year retrospective study by Sarraf-Yazdi et al. [41] concluded that cycling had kept steady or improved antimicrobial susceptibility profiles in gram-negative SICU infections. A review by Masterton et al. [45] cited 4 studies on cycling and mixing strategies and concluded that despite the potential for mathematical modeling to predict the effectiveness of mixing strategies, the role of such strategies continues to remain unclear. A similar review by Bal et al. [44] concluded that cycling and mixing may reduce resistance when used in conjunction with current approaches, but were not likely to have a significant impact when used individually.

Despite the conflicting data associated with antibiotic cycling and mixing strategies, other strategies such as antibiotic de-escalation have shown great promise [45]. Antibiotic de-escalation typically refers to narrowing or tailoring the breadth of antibiotic spectrum based on clinical response and laboratory measures, as well as early discontinuation of antimicrobial therapy when evidence of infection is no longer present (resulting in reduced therapy duration) [30]. To date, a number of trials supporting the use of de-escalation, specifically the reduction of antibiotic duration in common infections, have been published [40] [46]-[48]. Singh et al. [46] studied the use of short-duration antibiotic therapy in presumptive VAP patients, stopping antibiotics after 72 hours if the Clinical Pulmonary Infection Score was less than 6, and reported no difference in outcomes [resistance $(p=0.017)$, superinfection $(p=0.017)$, length of stay $(p=0.0001)$ or mortality $(p=0.0001)]$ when compared to patients receiving a full course of antibiotics. An RCT by Chastre et al. [47] demonstrated that appropriately treated venti- 
lator-acquired pneumonia (VAP) patients only required 8 days of empirical antibiotics, compared to the recommended 14-day course with no difference in clinical outcomes. These conclusions were later confirmed in a similar study by Micek et al. [48]. Hayashi et al. [40] reviewed the use of antimicrobial therapy in communityacquired pneumonia (CAP), VAP, bacterial meningitis, pyelonephritis, infective endocarditis and intra-abdominal infections, citing a number of trials reporting reductions in antibiotic duration with comparable clinical outcomes. With evidence-based data validating the clinical benefit to decreased antibiotic duration, de-escalation strategies on the measurement of serum biomarker levels, such as procalcitonin (PCT) has now become a major area of research.

PCT is a novel biomarker with unique properties that make it a potential serum marker for directing the clinical management of sepsis. In healthy individuals, serum PCT levels remain below $0.1 \mathrm{ng} / \mathrm{mL}$, but may increase a hundredfold or more in response to systemic bacterial infection [11]. PCT has been shown to rise rapidly after the onset of infection, starting to rise at 4 hours, with levels peaking between 8 and 24 hours [11]. Importantly, persistent elevation of PCT levels is only seen in bacterial infection and does not occur in viral infection or inflammatory processes [49]. Levels may increase in response to surgery, trauma or burns, but these increases are short-lived [49]. In the last decade, a growing literature pertaining to the value of PCT in sepsis diagnosis, prognostication and management has been explored [50]. Emerging research illustrates that PCT may even have merit extending beyond sepsis in the management of small bowel obstruction [51] [52], osteoarthritis [53], and necrotizing soft tissue infections [54]. This review critically evaluates all published literature with regards to the efficacy of PCT serum levels to guide antibiotic duration in septic adult patients, and discusses the strengths, limitations and future uses of PCT in sepsis therapy.

\section{Methods}

A comprehensive search of all published reports on the use of PCT levels to guide treatment of adult septic patients in both the intensive care unit (ICU) and non-ICU settings between 2007 and 2013 was conducted using PubMed and Google Scholar. The search focused on the value of PCT levels to guide antibiotic de-escalation, specifically reductions in duration of antibiotic administration. Keywords searched included, "procalcitonin", "PCT", "sepsis therapy", "sepsis biomarker", "antibiotic duration”, "antibiotic de-escalation" and "antimicrobial stewardship". Searches were limited to human clinical studies without any restriction based on language.

\section{Results}

Since 2007, 4 prospective randomized studies evaluating the utility of PCT serums levels in reducing antibiotic duration have been published [55]-[58], of which all report beneficial outcomes (Table 2). All four studies utilized a similar design, in which a "PCT-directed intervention arm" was compared with a "standard of care arm". The studies shared several common endpoints, specifically the reduction of antibiotic therapy duration (in days) and patient mortality, though each study utilized different criteria in determining the optimal timeframe for antibiotic discontinuation (Table 3). Nobre et al. [55] published the initial PCT level based intervention study involving 68 patients, and reported a 4-day reduction in antibiotic duration in the PCT arm $(p=0.003)$. Similarly, Hochreiter et al. [56] [57] demonstrated that patients in the PCT arm required 2 fewer days of antibiotics ( $p<$ $0.001)$ than the control arm, while Schroeder et al. found that the PCT intervention groups required 1.7 fewer days of antibiotics $(p<0.001)$. Finally, Bouadma et al. [58] performed the largest such study, involving 621 patients, and showed a 2.7-day reduction in antibiotics utilization $(p<0.0001)$ in the PCT arm. None of the 4 studies identified a significant difference in mortality between the PCT-directed intervention and control arms $(p>$ 0.05) [55]-[58].

\section{Discussion}

Since the earliest documentation of antibiotic resistance in the $1940 \mathrm{~s}$, several new drug classes have been established, with concomitant development of antibiotic resistance to many soon after their introduction [59] [60]. In past decades, medicine has witnessed a rise of new bacterial strains [61], including but not limited to MRSA (Methicillin-resistant Staphylococcus aureus), VISA (Vancomycin-intermediate Staphylococcus aureus), VRSA (Vancomycin-resistant Staphylococcus aureus), ESBL (Extended spectrum beta-lactamase), VRE (Vancomycin-resistant Enterococcus) and MDRAB (Multidrug-resistant bacteria acinetobacter baumanii). More recently 
Table 2. Summary of all prospective randomized controlled trials evaluating Procalcitonin-guided antibiotic de-escalation in adult sepsis patients conducted between 2007 and 2013.

\begin{tabular}{|c|c|c|c|c|c|c|c|c|c|}
\hline \multirow{2}{*}{$\begin{array}{l}\text { Study, } \\
\text { Year }\end{array}$} & \multirow{2}{*}{$\begin{array}{c}\text { Total } \\
\text { Patients (N) }\end{array}$} & \multicolumn{3}{|c|}{ PCT Arm } & \multicolumn{3}{|c|}{ Control Arm } & \multirow{2}{*}{$\begin{array}{c}{ }^{*} p \text {-value } \\
\text { (Tx duration) }\end{array}$} & \multirow[b]{2}{*}{ Outcomes } \\
\hline & & $\begin{array}{l}\text { Patients } \\
\text { (N) }\end{array}$ & $\begin{array}{l}\text { Tx duration } \\
\text { (d) }\end{array}$ & $\begin{array}{l}\text { Mortality } \\
\text { N (\%) }\end{array}$ & $\begin{array}{l}\text { Patients } \\
\text { (N) }\end{array}$ & $\begin{array}{l}\text { Tx duration } \\
\text { (d) }\end{array}$ & $\begin{array}{l}\text { Mortality }{ }^{\dagger}, \\
\text { N (\%) }\end{array}$ & & \\
\hline $\begin{array}{c}\text { Nobre, } 2007 \\
\text { [25] }\end{array}$ & 68 & 31 & $\begin{array}{c}6(95 \% \text { CI, } \\
4 \text { - 16)d }\end{array}$ & $5(16 \%)$ & 37 & $\begin{array}{c}10 \text { (95\% CI, } \\
3 \text { - 33) d }\end{array}$ & $6(16 \%)$ & $p=0.003$ & $\begin{array}{l}\text { ABx duration } \\
\text { decreased by } 4 \mathrm{~d} \\
\text { in PCT arm }\end{array}$ \\
\hline $\begin{array}{l}\text { Hochreiter, } \\
2009 \text { [26] }\end{array}$ & 110 & 57 & $5.9 \pm 1.7 \mathrm{~d}$ & 15 (26\%) & 53 & $7.9 \pm 0.5 \mathrm{~d}$ & $14(26 \%)$ & $p<0.001$ & $\begin{array}{l}\text { ABx duration } \\
\text { decreased by } 2 \mathrm{~d} \\
\text { in PCT arm }\end{array}$ \\
\hline $\begin{array}{l}\text { Schroeder, } \\
2009 \text { [27] }\end{array}$ & 27 & 14 & $6.6 \pm 1.1 \mathrm{~d}$ & 3 (21\%) & 13 & $8.3 \pm 0.7 \mathrm{~d}$ & $3(23 \%)$ & $p<0.001$ & $\begin{array}{l}\text { ABx duration } \\
\text { decreased by } 1.7 \mathrm{~d} \\
\text { in PCT arm }\end{array}$ \\
\hline $\begin{array}{l}\text { Bouadma, } \\
2010 \text { [28] }\end{array}$ & 621 & 307 & $\begin{array}{c}14.3 \pm 9.1 \mathrm{~d} \\
\text { w/o } \mathrm{ABx}\end{array}$ & 65 (21\%) & 314 & $\begin{array}{c}11.6 \pm 8.2 \mathrm{~d} \\
\text { w/o ABx }\end{array}$ & 64 (20\%) & $p<0.0001$ & $\begin{array}{l}\text { ABx duration } \\
\text { decreased by } 2.7 \mathrm{~d} \\
\text { in PCT arm }\end{array}$ \\
\hline
\end{tabular}

Abbreviations: $\mathrm{PCT}=$ procalcitonin, $\mathrm{N}=$ number of patients, $\mathrm{Tx}=$ treatment, w/o $=$ without, $\mathrm{ABx}=$ antibiotics, $\mathrm{d}=\mathrm{days}, \mathrm{SD}=\mathrm{standard}$ deviation. ${ }^{\dagger}$ : 28-day mortality; ${ }^{*} p$-value: statistical significance, $<0.05$.

Table 3. Antibiotic discontinuation criteria for prospective randomized controlled trials relating to Procalcitonin-guided antibiotic de-escalation in adult sepsis patients conducted between 2007 and 2013.

\begin{tabular}{cl}
\hline \multicolumn{1}{c}{ Study, Year } & \multicolumn{1}{c}{ Antibiotic Discontinuation Criteria } \\
\hline Nobre, 2007 [25] & $\begin{array}{l}\text { ABx discontinued when PCT levels decreased by } 90+\% \text { from initial value, but not prior to Day } 3 \text { (if baseline } \\
\text { PCT measured }<1 \mu \mathrm{g} / \mathrm{L} \text { ) or Day } 5 \text { (if baseline PCT measured } \geq 1 \mathrm{\mu g} / \mathrm{L} \text { ) }\end{array}$ \\
Hochreiter, $2009[26]$ & $\begin{array}{l}\text { ABx discontinued when PCT decreased to }<1 \mathrm{ng} / \mathrm{mL} \text {, or to } 25 \%-35 \% \text { of initial value over three days if } \\
\text { value was }>1 \mathrm{ng} / \mathrm{mL}\end{array}$ \\
Schroeder, 2009 [27] & $\begin{array}{l}\text { ABx discontinued when clinical signs of infection improved and PCT value decreased to }<1 \mathrm{ng} / \mathrm{mL} \text { or to } \\
<35 \% \text { of initial value within three days }\end{array}$ \\
Bouadma, 2010 [28] & ABx discontinued when PCT concentration $<80 \%$ of peak value, or absolute PCT concentration $<0.5 \mu \mathrm{g} / \mathrm{L}$ \\
\hline
\end{tabular}

Abbreviations: $\mathrm{PCT}=$ procalcitonin, $\mathrm{ABx}=$ antibiotics.

MDR strains such as New Delhi metalloenzyme (NDM) beta lactamase carrying bacteria and Klebsiella pneumoniae carbapenemase (KPC) producing bacteria have emerged leaving patients on single antibiotic regimens susceptible to serious infections [62]. Studies by Scheetz et al. [13], Liew et al. [14] and others [12] [27] [28] have independently demonstrated that $22 \%$ to $65 \%$ of hospital antibiotic use is inappropriate, implying that the indiscriminate use and overuse of antibiotics is the single most important modifiable cause of antibiotic resistance.

For decades, antibiotic resistance was considered a pharmaceutical problem to be combated with the development of ever stronger antibiotics. However, given the numerous barriers to the development and utilization of new antimicrobial agents, including rising costs of research and development, tight drug approval and regulatory pathways, and uncertain rates of future drug resistance, the rate of new antibiotic discovery and implementation is unlikely to keep up with development of drug resistance [62]-[64]. Between 1983 and 2007, there has been a significant decrease in the number of new antibiotic approvals [65], having some experts comment that, "The research pipeline for novel antibiotics is almost dry" [64]. Thus, the most time-efficient and cost-effective approach to combat resistance is by optimizing the use of currently-available antibiotics [64].

Current recommendations for antibiotic duration of therapy for various infections are based largely on anecdotal guidelines put forth by the Infectious Diseases Society of America (IDSA) or the American Thoracic Society (ATS) [65] [66]. However, as RCT based evidence presented itself, the guidelines for antibiotic therapy continually changed. Data on safety and clinical efficacy made available from five RCTs and two meta-analyses lead to a five day reduction in the recommended treatment duration for CAP [40] [67]-[73]. Two of the five 
RCTs were performed by Dunbar et al. [68] [69] from multiple US institutions comparing the efficacy of levofloxacin $750 \mathrm{mg}$ for 5 days versus $500 \mathrm{mg}$ for 10 days among 390 CAP patients and 149 atypical CAP patients with success rates $>90 \%$ in all groups. Addtionally, in the multicenter RCT conducted among 575 patient with mild to moderate CAP by Tellier et al. [70], telithromycin $800 \mathrm{mg}, 1$ dose daily, for 5 and 7 days was found to be as effective and as safe as clarithromycin $500 \mathrm{mg}$, twice daily, for 10 days with cure rates of $89.3 \%$ at 5 days, $88.8 \%$ at 7 days, and $91.8 \%$ at 10 days. File et al. [71] analyzed 469 CAP patients treated with gemfloxacin 320 mg daily with equal clinical resolution in those treated for 5 days versus 7 days (95\% versus 92\%, 95\% confidence interval: $-1.48,7.42$ ). A more recent study by el Moussaoui et al. [74] found that even a three-day course of amoxicillin for treating CAP yielded similar clinical outcomes to an eight-day course of antibiotics. VAP was traditionally treated with a 14 to 21-day course of antibiotics until the report by Chastre et al. [40] [47] resulted in IDSA/ATS-recommended treatment duration guidelines being reduced by 7 days. With current literature promoting antibiotic de-escalation the utilization of serum biomarkers, such as procalcitonin may become the standard of care to improve outcomes, decrease costs, and decelerate antibiotic resistance [40] [66].

A growing literature on procalcitonin suggests significant potential for its use in the diagnosis of sepsis, although its role in clinical medicine continues to be controversial. Evaluations of serum PCT levels as a tool to predict disease severity and mortality has been met with mixed results [75]-[79]. Serum PCT level-based antibiotic escalation protocols were studied by Jensen et al. [80] [81] with results suggesting serum PCT levels have no well-defined clinical value in guiding antibiotic spectrum, dose or duration. Furthermore, PCT-guided therapy conferred no survival advantage and instead was associated with increased end-organ damage in this study.

In contrast, studies evaluating the use of serum PCT as a guide for de-escalation have demonstrated significant potential. Scheutz et al. [32] [82], Stolz et al. [83] and Luyt et al. [84] have all reported PCT-guided antibiotic discontinuation to be clinically efficacious when used in the context of lower respiratory tract infection (LRTI), specifically CAP [32] [82] and VAP [82]-[84]. Scheutz et al. [32] compared PCT-guided antibiotic algorithms to standard of care therapy for CAP and VAP patients and reported decreased antibiotic duration (5.7 versus. 8.7 days; relative change, $-34.8 \%)$, with lower rates of antibiotic-associated adverse effects $(19.8 \%$ vs. 28.1\%) and comparable rates of adverse outcomes (15.4\% versus. 18.9\%). Stolz et al. [83] analyzed serum PCT level-based antibiotic discontinuation in VAP patients and reported a $27 \%$ reduction in overall antibiotic duration for the PCT study group. Finally, Luyt et al. [84] examined role of PCT serum levels for antibiotic discontinuation in VAP and ICU sepsis patients, concluding that despite its poor diagnostic value, serum PCT was useful as a prognostic marker and a guide for antibiotic discontinuation.

PCT-guided therapeutic interventions may provide a working solution to the ongoing issue of instituting stewardship practices, as the potential benefits of its use can lead to effective decreases in antibiotic duration and costs. However, there exist numerous barriers and limitations to ASPs and stewardship practices that must be overcome. One such obstacle is the determination of antibiotic spectrum and duration in patients undergoing empirical therapy for suspected infection. Several studies [29] [46] [85] have demonstrated that the prolonged use of antibiotics in cases of suspected infection does not necessarily provide any benefit, and may instead result in poor outcomes. Aarts et al. [85] established that empiric antimicrobial therapy continued for longer than 4 days in patients with suspected ICU-acquired nosocomial infection, resulted in increased 28-day mortality (32.1\%) when compared to patients with discounted antibiotics (7.7\%). Singh et al. [46] found that prolonged empiric treatment ( $>3$ days) with broad-spectrum antibiotics in ICU patients with pulmonary infiltrates resulted in increased ICU length of stay (14.7 days vs. 9.4) and increased rates of antimicrobial resistance/superinfection (35\%). Determining antibiotic spectrum and duration is a particularly important issue in the context of broadspectrum antibiotic use in suspected or culture positive bloodstream infection [86], especially when considering the delay in culture and antibiotic sensitivity testing results [87].

An additional obstacle in implanting stewardship practices is physician attitude and obstinacy. In a review by Masterton et al. [30] antibiotic de-escalation rates ranged from $10 \%$ in clinical practice studies to $70 \%$ in trials focusing on de-escalation, suggesting that the persuasion of clinicians to utilize de-escalation protocols is a barrier in and of itself. The authors concluded that, "There is a natural propensity, particularly in severe sepsis when the patient who has been very seriously ill is starting to get better, to stick with a treatment regimen that is working rather than change to an alternative agent” [30]. This observation, paired with the difficulty of making prescribing decisions independently, often results in stewardship recommendations having a low-priority for many clinicians [88]. Wester et al. [89] conducted a survey on 424 internal medicine physicians' attitude toward antibiotic use and reported that many are concerned about antimicrobial resistance in an inpatient setting, but 
hold beliefs that are often at odds with established evidence-based data. $87 \%$ of respondents found antimicrobial resistance to be a serious national issue, but only 55\% believed that the issue existed in their own hospitals [89]. Thus the study concluded that, "Many respondents see the risks as more theoretical than concrete, possibly weakening the impetus for behavior change" [89]. Though it may prove difficult to alter attitudes and perceptions rapidly, the primary solution appears to lie in the emphasis of education and behavioral modification.

Although APS may initially increase in overall cost of care and require additional manpower, stewardship practices are fiscally viable in both the long-term and short-term settings [90]-[93]. Beardsley et al. [93] studied on the financial impact of ASPs, and reported substantial savings as a result of reduced antibiotics expenditures amounting to approximately $\$ 920,070$ to $\$ 2,064,441$ per year. Moreover, Standiford et al. [91] reported financial benefits immediately following ASP implementation at one institution, noting a 37\% decrease in antimicrobial costs within the first three years. As such, ASPs have clearly demonstrated a capacity to cut hospital expenditures with continued long-term fiscal viability.

\section{Conclusion}

In summary, PCT-guided early cessation of antibiotic therapy in adult sepsis patients is associated with a significant decrease in antibiotic days, without any change in overall mortality. Given the success of these trials, PCT may find a place in antimicrobial stewardship programs aimed at limiting antibiotic therapy duration while decelerating the development of antibiotic resistance. There still exist numerous barriers to the widespread establishment and implementation of antimicrobial stewardship programs, including delays in diagnostic procedure data, physician attitude towards de-escalation, and frontend institutional expenses. However, solutions to these problems are present or forthcoming, and will ultimately reinforce modern medicine's drive towards positive progress in antimicrobial practices.

\section{Conflicts of Interest and Source of Funding}

All authors have no conflicts of interest, and accepted no financial sponsorship in producing and presenting this article.

\section{References}

[1] Gomes Silva, B.N., Andriolo, R.B., Atallah, A.N. and Salomao, R. (2010) De-Escalation of Antimicrobial Treatment for Adults with Sepsis, Severe Sepsis or Septic Shock. Cochrane Database of Systematic Reviews, 12, Article ID: CD007934.

[2] Martin, G.S., Mannino, D.M., Eaton, S. and Moss, M. (2003) The Epidemiology of Sepsis in the United States from 1979 through 2000. The New England Journal of Medicine, 348, 1546-1554. http://dx.doi.org/10.1056/NEJMoa022139

[3] Hall, M.J., Williams, S.N., De Frances, C.J. and Golosinskiy, A. (2011) Inpatient Care for Septicemia or Sepsis: A Challenge for Patients and Hospitals. NCHS Data Brief, 62, 1-8.

[4] Elixhauser, A., Friedman, B. and Stranges, E. (2006) Septicemia in U.S. Hospitals, 2009: Statistical Brief \#122.

[5] (2010) HCUP Facts and Figures: Statistics on Hospital-Based Care in the United States, 2008. Healthcare Cost and Utilization Project (HCUP). Agency for Healthcare Research and Quality, Rockville.

[6] Harbarth, S., Garbino, J., Pugin, J., Romand, J.A., Lew, D. and Pittet, D. (2003) Inappropriate Initial Antimicrobial Therapy and Its Effect on Survival in a Clinical Trial of Immunomodulating Therapy for Severe Sepsis. American Journal of Medicine, 115, 529-535. http://dx.doi.org/10.1016/j.amjmed.2003.07.005

[7] (2005) Guidelines for the Management of Adults with Hospital-Acquired, Ventilator-Associated, and Healthcare-Associated Pneumonia. American Journal of Respiratory and Critical Care Medicine, 171, 388-416. http://dx.doi.org/10.1164/rccm.200405-644ST

[8] Kumar, A., Roberts, D., Wood, K.E., Light, B., Parrillo, J.E., Sharma, S., Suppes, R., Feinstein, D., Zanotti, S., Taiberg, L., Gurka, D., Kumar, A. and Cheang, M. (2006) Duration of Hypotension before Initiation of Effective Antimicrobial Therapy Is the Critical Determinant of Survival in Human Septic Shock. Critical Care Medicine, 34, 1589-1596. http://dx.doi.org/10.1097/01.CCM.0000217961.75225.E9

[9] Micek, S.T., Lloyd, A.E., Ritchie, D.J., Reichley, R.M., Fraser, V.J. and Kollef, M.H. (2005) Pseudomonas Aeruginosa Bloodstream Infection: Importance of Appropriate Initial Antimicrobial Treatment. Antimicrobial Agents and Chemotherapy, 49, 1306-1311. http://dx.doi.org/10.1128/AAC.49.4.1306-1311.2005

[10] Proulx, N., Frechette, D., Toye, B., Chan, J. and Kravcik, S. (2005) Delays in the Administration of Antibiotics Are 
Associated with Mortality from Adult Acute Bacterial Meningitis. QJM, 98, 291-298. http://dx.doi.org/10.1093/qjmed/hci047

[11] Shehabi, Y. and Seppelt, I. (2008) Pro/Con Debate: Is Procalcitonin Useful for Guiding Antibiotic Decision Making in Critically Ill Patients? Critical Care, 12, 211. http://dx.doi.org/10.1186/cc6860

[12] Thursky, K.A., Buising, K.L., Bak, N., Macgregor, L., Street, A.C., Macintyre, C.R., Presneill, J.J., Cade, J.F. and Brown, G.V. (2006) Reduction of Broad-Spectrum Antibiotic Use with Computerized Decision Support in an Intensive Care Unit. International Journal for Quality in Health Care, 18, 224-231. http://dx.doi.org/10.1093/intqhc/mzi095

[13] Scheetz, M.H., Bolon, M.K., Postelnick, M., Noskin, G.A. and Lee, T.A. (2009) Cost-Effectiveness Analysis of an Antimicrobial Stewardship Team on Bloodstream Infections: A Probabilistic Analysis. Journal of Antimicrobial Chemotherapy, 63, 816-825. http://dx.doi.org/10.1093/jac/dkp004

[14] Liew, Y.X., Chlebicki, M.P., Lee, W., Hsu, L.Y. and Kwa, A.L. (2011) Use of Procalcitonin (PCT) to Guide Discontinuation of Antibiotic Use in an Unspecified Sepsis Is an Antimicrobial Stewardship Program (ASP). European Journal of Clinical Microbiology \& Infectious Diseases, 30, 853-855. http://dx.doi.org/10.1007/s10096-011-1165-6

[15] Shah, N.D., Hoffman, J.M., Vermeulen, L.C., Hunkler, R.J. and Hontz, K.M. (2003) Projecting Future Drug Expenditures-2003. American Journal of Health-System Pharmacy, 60, 137-149.

[16] Hoffman, J.M., Shah, N.D., Vermeulen, L.C., Hunkler, R.J. and Hontz, K.M. (2004) Projecting Future Drug Expenditures-2004. American Journal of Health-System Pharmacy, 61, 145-158.

[17] Hoffman, J.M., Shah, N.D., Vermeulen, L.C., Hunkler, R.J. and Hontz, K.M. (2005) Projecting Future Drug Expenditures-2005. American Journal of Health-System Pharmacy, 62, 149-167.

[18] Hoffman, J.M., Shah, N.D., Vermeulen, L.C., Schumock, G.T., Grim, P., Hunkler, R.J. and Hontz, K.M. (2006) Projecting Future Drug Expenditures-2006. American Journal of Health-System Pharmacy, 63, 123-138. http://dx.doi.org/10.2146/ajhp050446

[19] Hoffman, J.M., Shah, N.D., Vermeulen, L.C., Schumock, G.T., Grim, P., Hunkler, R.J. and Hontz, K.M. (2007) Projecting Future Drug Expenditures-2007. American Journal of Health-System Pharmacy, 64, 298-314. http://dx.doi.org/10.2146/ajhp060545

[20] Hoffman, J.M., Shah, N.D., Vermeulen, L.C., Doloresco, F., Grim, P., Hunkler, R.J., Hontz, K.M. and Schumock, G.T. (2008) Projecting Future Drug Expenditures-2008. American Journal of Health-System Pharmacy, 65, $234-253$. http://dx.doi.org/10.2146/ajhp070629

[21] Hoffman, J.M., Shah, N.D., Vermeulen, L.C., Doloresco, F., Martin, P.K., Blake, S., Matusiak, L., Hunkler, R.J. and Schumock, G.T. (2009) Projecting Future Drug Expenditures-2009. American Journal of Health-System Pharmacy, 66, 237-257. http://dx.doi.org/10.2146/ajhp080636

[22] Hoffman, J.M., Doloresco, F., Vermeulen, L.C., Shah, N.D., Matusiak, L., Hunkler, R.J. and Schumock, G.T. (2010) Projecting Future Drug Expenditures-2010. American Journal of Health-System Pharmacy, 67, 919-928. http://dx.doi.org/10.2146/ajhp100068

[23] Doloresco, F., Fominaya, C., Schumock, G.T., Vermeulen, L.C., Matusiak, L., Hunkler, R.J., Shah, N.D. and Hoffman, J.M. (2011) Projecting Future Drug Expenditures-2011. American Journal of Health-System Pharmacy, 68, 921-932. http://dx.doi.org/10.2146/ajhp100712

[24] Hoffman, J.M., Li, E., Doloresco, F., Matusiak, L., Hunkler, R.J., Shah, N.D., Vermeulen, L.C. and Schumock, G.T. (2012) Projecting Future Drug Expenditures-2012. American Journal of Health-System Pharmacy, 69, 405-421. http://dx.doi.org/10.2146/ajhp110697

[25] Hoffman, J.M., Li, E., Doloresco, F., Matusiak, L., Hunkler, R.J., Shah, N.D., Vermeulen, L.C., Schumock, G.T. (2013) Projecting Future Drug Expenditures in U.S. Nonfederal Hospitals and Clinics-2013. American Journal of HealthSystem Pharmacy, 70, 525-539. http://dx.doi.org/10.2146/ajhp120759

[26] Finland, M. (1979) Emergence of Antibiotic Resistance in Hospitals, 1935-1975. Clinical Infectious Diseases, 1, 4-21. http://dx.doi.org/10.1093/clinids/1.1.4

[27] Deege, M.P. and Paterson, D.L. (2011) Reducing the Development of Antibiotic Resistance in Critical Care Units. Current Pharmaceutical Biotechnology, 12, 2062-2069. http://dx.doi.org/10.2174/138920111798808301

[28] Van Duijn, P.J., Dautzenberg, M.J. and Oostdijk, E.A. (2011) Recent Trends in Antibiotic Resistance in European ICUs. Current Opinion in Critical Care, 17, 658-665. http://dx.doi.org/10.1097/MCC.0b013e32834c9d87

[29] Lawrence, K.L. and Kollef, M.H. (2009) Antimicrobial Stewardship in the Intensive Care Unit: Advances and Obstacles. American Journal of Respiratory and Critical Care Medicine, 179, 434-438. http://dx.doi.org/10.1164/rccm.200809-1394CP

[30] Masterton, R.G. (2011) Antibiotic De-Escalation. Critical Care Clinics, 27, 149-162. http://dx.doi.org/10.1016/j.ccc.2010.09.009 
[31] Schuetz, P., Albrich, W. and Mueller, B. (2011) Procalcitonin for Diagnosis of Infection and Guide to Antibiotic Decisions: Past, Present and Future. BMC Medicine, 9, 107. http://dx.doi.org/10.1186/1741-7015-9-107

[32] Schuetz, P., Christ-Crain, M., Thomann, R., Falconnier, C., Wolbers, M., Widmer, I., Neidert, S., Fricker, T., Blum, C., Schild, U., Regez, K., Schoenenberger, R., Henzen, C., Bregenzer, T., Hoess, C., Krause, M., Bucher, H.C., Zimmerli, W. and Mueller, B. (2009) Effect of Procalcitonin-Based Guidelines vs Standard Guidelines on Antibiotic Use in Lower Respiratory Tract Infections: The ProHOSP Randomized Controlled Trial. The Journal of the American Medical Association, 302, 1059-1066. http://dx.doi.org/10.1001/jama.2009.1297

[33] Drew, R.H. (2009) Antimicrobial Stewardship Programs: How to Start and Steer a Successful Program. Journal of Managed Care Pharmacy, 15, S18-S23.

[34] Goldmann, D.A., Weinstein, R.A., Wenzel, R.P., Tablan, O.C., Duma, R.J., Gaynes, R.P., Schlosser, J. and Martone, W.J. (1996) Strategies to Prevent and Control the Emergence and Spread of Antimicrobial-Resistant Microorganisms in Hospitals. A challenge to Hospital Leadership. The Journal of the American Medical Association, 275, $234-240$. http://dx.doi.org/10.1001/jama.1996.03530270074035

[35] Apisarnthanarak, A., Buppunharun, W., Tiengrim, S., Sawanpanyalert, P. and Aswapokee, N. (2009) An Overview of Antimicrobial Susceptibility Patterns for Gram-Negative Bacteria from the National Antimicrobial Resistance Surveillance Thailand (NARST) Program from 2000 to 2005. Journal of the Medical Association of Thailand, 92, S91-S94.

[36] Tseng, S.H., Lee, C.M., Lin, T.Y., Chang, S.C., Chuang, Y.C., Yen, M.Y., Hwang, K.P., Leu, H.S., Yen, C.C. and Chang, F.Y. (2012) Combating Antimicrobial Resistance: Antimicrobial Stewardship Program in Taiwan. Journal of Microbiology, Immunology and Infection, 45, 79-89. http://dx.doi.org/10.1016/j.jmii.2012.03.007

[37] Allerberger, F., Lechner, A., Wechsler-Fördös, A. and Gareis, R. (2008) Optimization of Antibiotic Use in HospitalsAntimicrobial Stewardship and the EU Project ABS International. Chemotherapy, 54, 260-267. http://dx.doi.org/10.1159/000149716

[38] Allerberger, F., Frank, A. and Gareis, R. (2008) Antibiotic Stewardship through the EU Project “ABS International”. Wiener klinische Wochenschrift, 120, 256-263. http://dx.doi.org/10.1007/s00508-008-0966-9

[39] George, P. and Morris, A.M. (2010) Pro/Con Debate: Should Antimicrobial Stewardship Programs Be Adopted Universally in the Intensive Care Unit? Critical Care, 14, 205. http://dx.doi.org/10.1186/cc8219

[40] Hayashi, Y. and Paterson, D.L. (2011) Strategies for Reduction in Duration of Antibiotic Use in Hospitalized Patients. Clinical Infectious Diseases, 52, 1232-1240. http://dx.doi.org/10.1093/cid/cir063

[41] Sarraf-Yazdi, S., Sharpe, M., Bennett, K.M., Dotson, T.L., Anderson, D.J. and Vaslef, S.N. (2012) A 9-Year Retrospective Review of Antibiotic Cycling in a Surgical Intensive Care Unit. Journal of Surgical Research, 176, e73-e78. http://dx.doi.org/10.1016/j.jss.2011.12.014

[42] Beardmore, R.E. and Pena-Miller, R. (2010) Antibiotic Cycling Versus Mixing: The Difficulty of Using Mathematical Models to Definitively Quantify Their Relative Merits. Mathematical Biosciences and Engineering, 7, 923-933. http://dx.doi.org/10.3934/mbe.2010.7.923

[43] Kollef, M.H. (2006) Is Antibiotic Cycling the Answer to Preventing the Emergence of Bacterial Resistance in the Intensive Care Unit? Clinical Infectious Diseases, 43, S82-S88. http://dx.doi.org/10.1086/504484

[44] Bal, A.M., Kumar, A. and Gould, I.M. (2010) Antibiotic Heterogeneity: From Concept to Practice. Annals of the New York Academy of Sciences, 1213, 81-91. http://dx.doi.org/10.1111/j.1749-6632.2010.05867.x

[45] Masterton, R.G. (2010) Antibiotic Heterogeneity. International Journal of Antimicrobial Agents, 36, S15-S18. http://dx.doi.org/10.1016/S0924-8579(10)70005-4

[46] Singh, N., Rogers, P., Atwood, C.W., Wagener, M.M. and Yu, V.L. (2000) Short-Course Empiric Antibiotic Therapy for Patients with Pulmonary Infiltrates in the Intensive Care Unit. A Proposed Solution for Indiscriminate Antibiotic Prescription. American Journal of Respiratory and Critical Care Medicine, 162, 505-511. http://dx.doi.org/10.1164/ajrccm.162.2.9909095

[47] Chastre, J., Wolff, M., Fagon, J.Y., Chevret, S., Thomas, F., Wermert, D., Clementi, E., Gonzalez, J., Jusserand, D., Asfar, P., Perrin, D., Fieux, F. and Aubas, S. (2003) Comparison of 8 vs 15 days of Antibiotic Therapy for VentilatorAssociated Pneumonia in Adults: A Randomized Trial. The Journal of the American Medical Association, 290, 2588-2598. http://dx.doi.org/10.1001/jama.290.19.2588

[48] Micek, S.T., Ward, S., Fraser, V.J. and Kollef, M.H. (2004) A Randomized Controlled Trial of an Antibiotic Discontinuation Policy for Clinically Suspected Ventilator-Associated Pneumonia. Chest, 125, 1791-1799. http://dx.doi.org/10.1378/chest.125.5.1791

[49] Gonsalves, M.D. and Sakr, Y. (2010) Early Identification of Sepsis. Current Infectious Disease Reports, 12, 329-335. http://dx.doi.org/10.1007/s11908-010-0122-3

[50] Lavrentieva, A., Papadopoulou, S., Kioumis, J., Kaimakamis, E. and Bitzani, M. (2012) PCT as a Diagnostic and Prognostic Tool in Burn Patients. Whether Time Course Has a Role in Monitoring Sepsis Treatment. Burns, 38, 356- 
363. http://dx.doi.org/10.1016/j.burns.2011.08.021

[51] Cosse, C., Regimbeau, J.M., Fuks, D., Mauvais, F. and Scotte, M. (2013) Serum Procalcitonin for Predicting the Failure of Conservative Management and the Need for Bowel Resection in Patients with Small Bowel Obstruction. Journal of The American College of Surgeons, 216, 997-1004. http://dx.doi.org/10.1016/j.jamcollsurg.2012.12.051

[52] Markogiannakis, H., Memos, N., Messaris, E., Dardamanis, D., Larentzakis, A., Papanikolaou, D., Zografos, G.C. and Manouras, A. (2011) Predictive Value of Procalcitonin for Bowel Ischemia and Necrosis in Bowel Obstruction. Surgery, 149, 394-403. http://dx.doi.org/10.1016/j.surg.2010.08.007

[53] Shen, C.J., Wu, M.S., Lin, K.H., Lin, W.L., Chen, H.C., Wu, J.Y., Lee, M.C. and Lee, C.C. (2013) The Use of Procalcitonin in the Diagnosis of Bone and Joint Infection: A Systemic Review and Meta-Analysis. European Journal of Clinical Microbiology \& Infectious Diseases, 32, 807-814. http://dx.doi.org/10.1007/s10096-012-1812-6

[54] Friederichs, J., Hutter, M., Hierholzer, C., Novotny, A., Friess, H., Buhren, V. and Hungerer, S. (2013) Procalcitonin Ratio as a Predictor of Successful Surgical Treatment of Severe Necrotizing Soft Tissue Infections. The American Journal of Surgery, 206, 368-373. http://dx.doi.org/10.1016/j.amjsurg.2012.11.024

[55] Nobre, V., Harbarth, S., Graf, J.D., Rohner, P. and Pugin, J. (2008) Use of Procalcitonin to Shorten Antibiotic Treatment Duration in Septic Patients: A Randomized Trial. American Journal of Respiratory and Critical Care Medicine, 177, 498-505. http://dx.doi.org/10.1164/rccm.200708-1238OC

[56] Hochreiter, M., Kohler, T., Schweiger, A.M., Keck, F.S., Bein, B., von, S.T. and Schroeder, S. (2009) Procalcitonin to Guide Duration of Antibiotic Therapy in Intensive Care Patients: A Randomized Prospective Controlled Trial. Critical Care, 13, R83. http://dx.doi.org/10.1186/cc7903

[57] Schroeder, S., Hochreiter, M., Koehler, T., Schweiger, A.M., Bein, B., Keck, F.S. and von, S.T. (2009) Procalcitonin (PCT)-Guided Algorithm Reduces Length of Antibiotic Treatment in Surgical Intensive Care Patients with Severe Sepsis: Results of a Prospective Randomized Study. Langenbeck’s Archives of Surgery, 394, 221-226. http://dx.doi.org/10.1007/s00423-008-0432-1

[58] Bouadma, L., Luyt, C.E., Tubach, F., Cracco, C., Alvarez, A., Schwebel, C., Schortgen, F., Lasocki, S., Veber, B., Dehoux, M., Bernard, M., Pasquet, B., Regnier, B., Brun-Buisson, C., Chastre, J. and Wolff, M. (2010) Use of Procalcitonin to Reduce Patients' Exposure to Antibiotics in Intensive Care Units (PRORATA Trial): A Multicentre Randomised Controlled Trial. The Lancet, 375, 463-474. http://dx.doi.org/10.1016/S0140-6736(09)61879-1

[59] Kirby, W.M. and Rantz, L.A. (1942) Sulfonamide Resistance. California and Western Medicine, 57, 174-175.

[60] Hawser, S. (2012) Surveillance Programmes and Antibiotic Resistance: Worldwide and Regional Monitoring of Antibiotic Resistance Trends. Handbook of Experimental Pharmacology, 211, 31-43.

[61] Pendleton, J.N., Gorman, S.P. and Gilmore, B.F. (2013) Clinical Relevance of the ESKAPE Pathogens. Expert Review of Anti-Infective Therapy, 11, 297-308. http://dx.doi.org/10.1586/eri.13.12

[62] Gould, I.M. and Bal, A.M. (2013) New Antibiotic Agents in the Pipeline and How They Can Help Overcome Microbial Resistance. Virulence, 4, 185-191. http://dx.doi.org/10.4161/viru.22507

[63] Canton, R. and Bryan, J. (2012) Global Antimicrobial Resistance: From Surveillance to Stewardship. Part 1: Surveillance and Risk Factors for Resistance. Expert Review of Anti-Infective Therapy, 10, 1269-1271. http://dx.doi.org/10.1586/eri.12.120

[64] Canton, R. and Bryan, J. (2012) Global Antimicrobial Resistance: From Surveillance to Stewardship. Part 2: Stewardship Initiatives. Expert Review of Anti-Infective Therapy, 10, 1375-1377. http://dx.doi.org/10.1586/eri.12.140

[65] Marr, J.J., Moffet, H.L. and Kunin, C.M. (1988) Guidelines for Improving the Use of Antimicrobial Agents in Hospitals: A Statement by the Infectious Diseases Society of America. The Journal of Infectious Diseases, 157, 869-876. http://dx.doi.org/10.1093/infdis/157.5.869

[66] Wlodaver, C. and May, C.P. (2012) Antibiotic Stewardship: Using Clinical Guidelines to Control Antibiotic Overuse and Deter Microbial Adaptation. Infectious Disease in Clinical Practice, 20, 12-17. http://dx.doi.org/10.1097/IPC.0b013e31822e9bba

[67] Leophonte, P., Choutet, P., Gaillat, J., Petitpretz, P., Portier, H., Montestruc, F., Pecking, M. and de Bels, F. (2002) Efficacy of a Ten Day Course of Ceftriaxone Compared to a Shortened Five Day Course in the Treatment of Community-Acquired Pneumonia in Hospitalized Adults with Risk Factors. Médecine et Maladies Infectieuses, 32, 369-381.

[68] Dunbar, L.M., Wunderink, R.G., Habib, M.P., Smith, L.G., Tennenberg, A.M., Khashab, M.M., Wiesinger, B.A., Xiang, J.X., Zadeikis, N. and Kahn, J.B. (2003) High-Dose, Short-Course Levofloxacin for Community-Acquired Pneumonia: A New Treatment Paradigm. Clinical Infectious Diseases, 37, 752-760. http://dx.doi.org/10.1086/377539

[69] Dunbar, L.M., Khashab, M.M., Kahn, J.B., Zadeikis, N., Xiang, J.X. and Tennenberg, A.M. (2004) Efficacy of 750-MG, 5-Day Levofloxacin in the Treatment of Community-Acquired Pneumonia Caused by Atypical Pathogens. Current Medical Research and Opinion, 20, 555-563. http://dx.doi.org/10.1185/030079904125003304

[70] Tellier, G., Niederman, M.S., Nusrat, R., Patel, M. and Lavin, B. (2004) Clinical and Bacteriological Efficacy and 
Safety of 5 and 7 Day Regimens of Telithromycin Once Daily Compared with a 10 Day Regimen of Clarithromycin Twice Daily in Patients with Mild to Moderate Community-Acquired Pneumonia. Journal of Antimicrobial Chemotherapy, 54, 515-523. http://dx.doi.org/10.1093/jac/dkh356

[71] File Jr., T.M., Mandell, L.A., Tillotson, G., Kostov, K. and Georgiev, O. (2007) Gemifloxacin Once Daily for 5 Days versus 7 Days for the Treatment of Community-Acquired Pneumonia: A Randomized, Multicentre, Double-Blind Study. Journal of Antimicrobial Chemotherapy, 60, 112-120. http://dx.doi.org/10.1093/jac/dkm119

[72] Li, J.Z., Winston, L.G., Moore, D.H. and Bent, S. (2007) Efficacy of Short-Course Antibiotic Regimens for Community-Acquired Pneumonia: A Meta-Analysis. American Journal of Medicine, 120, 783-790. http://dx.doi.org/10.1016/j.amjmed.2007.04.023

[73] Dimopoulos, G., Matthaiou, D.K., Karageorgopoulos, D.E., Grammatikos, A.P., Athanassa, Z. and Falagas, M.E. (2008) Short-Versus Long-Course Antibacterial Therapy for Community-Acquired Pneumonia: A Meta-Analysis. Drugs, 68, 1841-1854. http://dx.doi.org/10.2165/00003495-200868130-00004

[74] el Moussaoui, R., de Borgie, C.A., van den Broek, P., Hustinx, W.N., Bresser, P., van den Berk, G.E., Poley, J.W., van den Berg, B., Krouwels, F.H., Bonten, M.J., Weenink, C., Bossuyt, P.M., Speelman, P., Opmeer, B.C. and Prins, J.M. (2006) Effectiveness of Discontinuing Antibiotic Treatment after Three Days versus Eight Days in Mild to Moderate-Severe Community Acquired Pneumonia: Randomised, Double Blind Study. British Medical Journal, 332, 1355. http://dx.doi.org/10.1136/bmj.332.7554.1355

[75] Sudhir, U., Venkatachalaiah, R.K., Kumar, T.A., Rao, M.Y. and Kempegowda, P. (2011) Significance of Serum Procalcitonin in Sepsis. Indian Journal of Critical Care Medicine, 15, 1-5. http://dx.doi.org/10.4103/0972-5229.78214

[76] Whang, K.T., Steinwald, P.M., White, J.C., Nylen, E.S., Snider, R.H., Simon, G.L., Goldberg, R.L. and Becker, K.L. (1998) Serum Calcitonin Precursors in Sepsis and Systemic Inflammation. The Journal of Clinical Endocrinology \& Metabolism, 83, 3296-3301.

[77] Selberg, O., Hecker, H., Martin, M., Klos, A., Bautsch, W. and Kohl, J. (2000) Discrimination of Sepsis and Systemic Inflammatory Response Syndrome by Determination of Circulating Plasma Concentrations of Procalcitonin, Protein Complement 3a, and Interleukin-6. Critical Care Medicine, 28, 2793-2798. http://dx.doi.org/10.1097/00003246-200008000-00019

[78] Castelli, G.P., Pognani, C., Meisner, M., Stuani, A., Bellomi, D. and Sgarbi, L. (2004) Procalcitonin and C-Reactive Protein during Systemic Inflammatory Response Syndrome, Sepsis and Organ Dysfunction. Critical Care, 8, R234R242. http://dx.doi.org/10.1186/cc2877

[79] Dahaba, A.A., Hagara, B., Fall, A., Rehak, P.H., List, W.F. and Metzler, H. (2006) Procalcitonin for Early Prediction of Survival Outcome in Postoperative Critically Ill Patients with Severe Sepsis. British Journal of Anaesthesia, 97, 503-508. http://dx.doi.org/10.1093/bja/ael181

[80] Jensen, J.U., Hein, L., Lundgren, B., Bestle, M.H., Mohr, T.T., Andersen, M.H., Thornberg, K.J., Loken, J., Steensen, M., Fox, Z., Tousi, H., Soe-Jensen, P., Lauritsen, A.O., Strange, D., Petersen, P.L., Reiter, N., Hestad, S., Thormar, K., Fjeldborg, P., Larsen, K.M., Drenck, N.E., Ostergaard, C., Kjaer, J., Grarup, J. and Lundgren, J.D. (2011) Procalcitonin-Guided Interventions against Infections to Increase Early Appropriate Antibiotics and Improve Survival in the Intensive Care Unit: A Randomized Trial. Critical Care Medicine, 39, 2048-2058. http://dx.doi.org/10.1097/CCM.0b013e31821e8791

[81] Jensen, J.U., Lundgren, B., Hein, L., Mohr, T., Petersen, P.L., Andersen, L.H., Lauritsen, A.O., Hougaard, S., Mantoni, T., Bomler, B., Thornberg, K.J., Thormar, K., Loken, J., Steensen, M., Carl, P., Petersen, J.A., Tousi, H., Soe-Jensen, P., Bestle, M., Hestad, S., Andersen, M.H., Fjeldborg, P., Larsen, K.M., Rossau, C., Thomsen, C.B., et al. (2008) The Procalcitonin And Survival Study (PASS)-A Randomised Multi-Center Investigator-Initiated Trial to Investigate whether Daily Measurements Biomarker Procalcitonin and Pro-Active Diagnostic and Therapeutic Responses to Abnormal Procalcitonin Levels, Can Improve Survival in Intensive Care unit Patients. Calculated Sample Size (Target Population): 1000 Patients. BMC Infectious Diseases, 8, 91. http://dx.doi.org/10.1186/1471-2334-8-91

[82] Schuetz, P., Albrich, W., Christ-Crain, M., Chastre, J. and Mueller, B. (2010) Procalcitonin for Guidance of Antibiotic Therapy. Expert Review of Anti-Infective Therapy, 8, 575-587. http://dx.doi.org/10.1586/eri.10.25

[83] Stolz, D., Smyrnios, N., Eggimann, P., Pargger, H., Thakkar, N., Siegemund, M., Marsch, S., Azzola, A., Rakic, J., Mueller, B. and Tamm, M. (2009) Procalcitonin for Reduced Antibiotic Exposure in Ventilator-Associated Pneumonia: A Randomised Study. European Respiratory Journal, 34, 1364-1375. http://dx.doi.org/10.1183/09031936.00053209

[84] Luyt, C.E., Combes, A., Trouillet, J.L. and Chastre, J. (2011) Value of the Serum Procalcitonin Level to Guide Antimicrobial Therapy for Patients with Ventilator-Associated Pneumonia. Seminars in Respiratory and Critical Care Medicine, 32, 181-187. http://dx.doi.org/10.1055/s-0031-1275530

[85] Aarts, M.A., Brun-Buisson, C., Cook, D.J., Kumar, A., Opal, S., Rocker, G., Smith, T., Vincent, J.L. and Marshall, J.C. (2007) Antibiotic Management of Suspected Nosocomial ICU-Acquired Infection: Does Prolonged Empiric Therapy Improve Outcome? Intensive Care Medicine, 33, 1369-1378. 
[86] Romano, J. (2009) Labs Take New Role in Antibiotic Stewardship, Championing Improved Diagnoses, Guiding Therapy, Saving Lives, and Cutting Costs. Medical Laboratory Observer, 41, 16-18.

[87] Tenover, F.C. (2010) Potential Impact of Rapid Diagnostic Tests on Improving Antimicrobial Use. Annals of the New York Academy of Sciences, 1213, 70-80.

[88] Gould, I.M. (2009) Controversies in Infection: Infection Control or Antibiotic Stewardship to Control Healthcare-Acquired Infection? Journal of Hospital Infection, 73, 386-391. http://dx.doi.org/10.1016/j.jhin.2009.02.023

[89] Wester, C.W., Durairaj, L., Evans, A.T., Schwartz, D.N., Husain, S. and Martinez, E. (2002) Antibiotic Resistance: A Survey of Physician Perceptions. JAMA Internal Medicine, 162, 2210-2216. http://dx.doi.org/10.1001/archinte.162.19.2210

[90] Srinivasan, A. and Fishman, N. (2012) Antimicrobial Stewardship 2012: Science Driving Practice. Infection Control and Hospital Epidemiology, 33, 319-321. http://dx.doi.org/10.1086/664908

[91] Standiford, H.C., Chan, S., Tripoli, M., Weekes, E. and Forrest, G.N. (2012) Antimicrobial Stewardship at a Large Tertiary Care Academic Medical Center: Cost Analysis before, during, and after a 7-Year Program. Infection Control and Hospital Epidemiology, 33, 338-345. http://dx.doi.org/10.1086/664909

[92] Stevenson, K.B., Balada-Llasat, J.M., Bauer, K., Deutscher, M., Goff, D., Lustberg, M., Pancholi, P., Reed, E., Smeenk, D., Taylor, J. and West, J. (2012) The Economics of Antimicrobial Stewardship: The Current State of the Art and Applying the Business Case Model. Infection Control and Hospital Epidemiology, 33, 389-397. http://dx.doi.org/10.1086/664910

[93] Beardsley, J.R., Williamson, J.C., Johnson, J.W., Luther, V.P., Wrenn, R.H. and Ohl, C.C. (2012) Show Me the Money: Long-Term Financial Impact of an Antimicrobial Stewardship Program. Infection Control and Hospital Epidemiology, 33, 398-400. http://dx.doi.org/10.1086/664922 
Scientific Research Publishing (SCIRP) is one of the largest Open Access journal publishers. It is currently publishing more than 200 open access, online, peer-reviewed journals covering a wide range of academic disciplines. SCIRP serves the worldwide academic communities and contributes to the progress and application of science with its publication.

Other selected journals from SCIRP are listed as below. Submit your manuscript to us via either submit@scirp.org or Online Submission Portal.
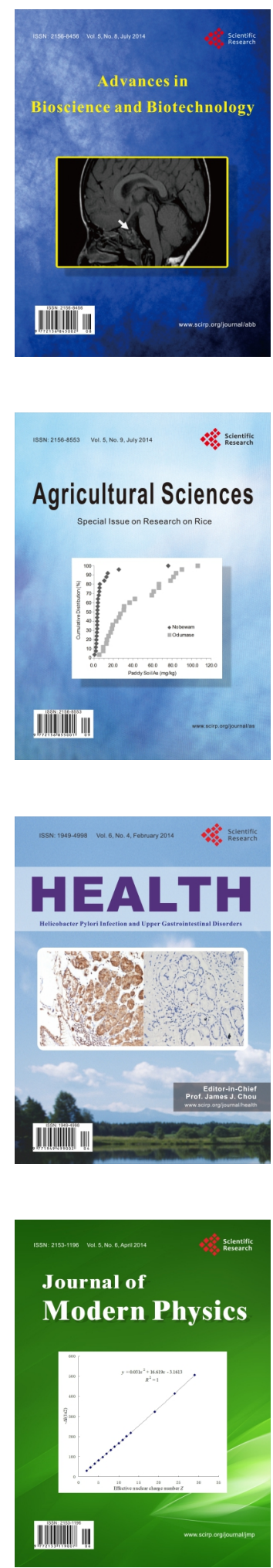
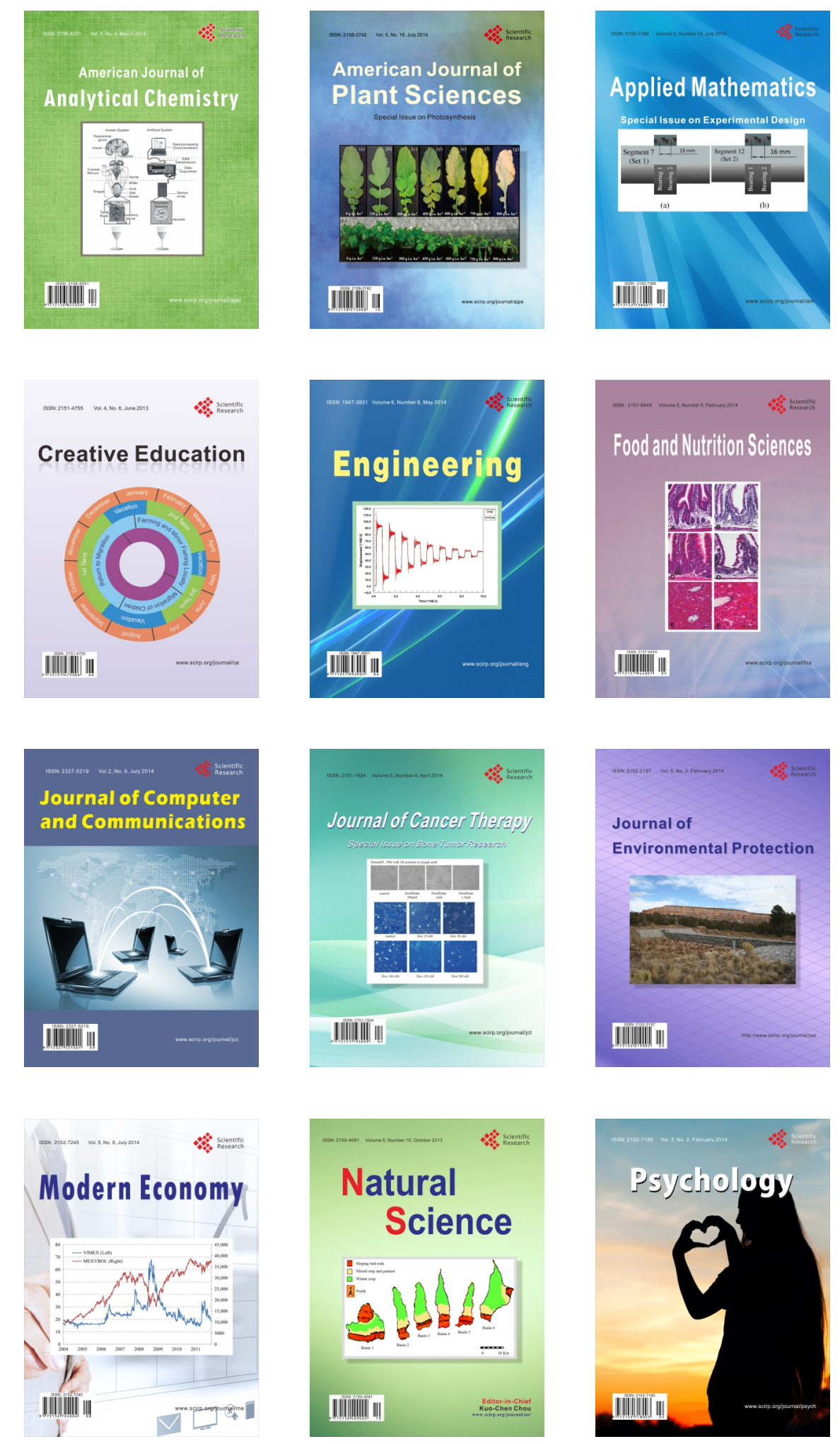